\title{
Clinical swallowing prognostic indicators in patients with acute ischemic stroke
}

\author{
Indicadores de prognóstico clínico da deglutição em pacientes com acidente vascular \\ cerebral isquêmico
}

\author{
Karoline Kussik de Almeida LEITE'; Fernanda Chiarion SASSI², Gisele Chagas de MEDEIROS ${ }^{1}$, Luiz Roberto \\ COMERLATTI ${ }^{3}$, Claudia Regina Furquim de ANDRADE²
}

\begin{abstract}
A swallowing disorder is present in more than $50 \%$ of patients with acute stroke. Objective: To identify clinical prognostic indicators of the swallowing function in a population with acute ischemic stroke and to determine prioritization indicators for swallowing rehabilitation. Methods: Participants were adults admitted to the emergency room who were diagnosed with acute ischemic stroke. Data gathering involved a swallowing assessment to determine the functional level of swallowing (American Speech-Language-Hearing Association National Outcome Measurement System - ASHA NOMS) and the verification of demographic and clinical variables. Results: The study sample included 295 patients. For analysis purposes, patients were grouped as follows: ASHA NOMS levels 1 and $2-$ ASHA1 ( $n=51$ ); levels 3, 4 and 5 - ASHA2 ( $n=96)$; levels 6 and 7 - ASHA3 $(n=148)$. Statistical analyses indicated that patients who presented a poorer swallowing function (ASHA1) were older (age $\geq 70$ years); had anterior circulation infarct; had lower scores on the Glasgow Coma Scale (GCS $\leq 14$ points); took longer to initiate swallowing rehabilitation; had longer hospital stays; made more use of alternative feeding methods; needed more sessions of swallowing rehabilitation to remove alternate feeding methods; took longer to return to oral feeding and had poorer outcomes (fewer individuals discharged from swallowing rehabilitation sessions and increased mortality). Conclusion: Patients with acute ischemic stroke, admitted to the emergency room, aged $\geq 70$ years, score on the GCS $\leq 14$, anterior circulation infarct and dementia should be prioritized for swallowing assessment and rehabilitation.
\end{abstract}

Keywords: Speech, languages and hearing sciences; deglutition; deglutiton disorders; stroke; indicators of health services.

\section{RESUMO}

Alterações da deglutição são observadas em mais de 50\% dos pacientes com acidente vascular cerebral isquêmico (AVCI) agudo. Objetivo: Identificar os indicadores de prognóstico clínico da funcionalidade da deglutição na população com AVCl em fase aguda, visando o estabelecimento de indicadores de priorização de atendimento fonoaudiológico. Métodos: Participaram do estudo adultos admitidos em Pronto Socorro (PS) com AVCI. As etapas de coleta de dados envolveram avaliação fonoaudiológica para determinação do nível funcional da deglutição (American Speech-Language-Hearing Association National Outcome Measurement System - ASHA NOMS) e a coleta de variáveis demográficas e clínicas. Resultados: A amostra do estudo incluiu 295 pacientes agrupados de acordo com os níveis ASHA NOMS: níveis 1 e 2 - ASHA1 ( $n$ = 51); níveis 3, 4 e 5 - ASHA2 ( $n=96)$; níveis 6 e 7 - ASHA3 ( $n=148)$. As análises indicaram os seguintes resultados significantes: pacientes com pior funcionalidade da deglutição (ASHA1) apresentaram média de idade superior a 70 anos, maior comprometimento da circulação cerebral anterior pós-AVCl, pior pontuação na Escala de Coma de Glasgow (ECG $\leq 14$ pontos), demoraram mais tempo para iniciar o atendimento fonoaudiológico, permaneceram mais tempo internados no hospital, fizeram mais uso de via alternativa de alimentação, necessitaram de mais sessões fonoaudiológicas para retirada da via alternativa de alimentação, demoraram mais tempo para retornar para alimentação por via oral e apresentaram pior desfecho (um número menor de indivíduos recebeu alta fonoaudiológica e apresentaram mortalidade aumentada). Conclusão: Pacientes com AVCl agudo, admitidos em PS, que apresentem idade $\geq 70$ anos, pontuação na ECG $\leq 14$, com comprometimento do sistema circulatório cerebral anterior e demência, devem ser priorizados no atendimento fonoaudiológico.

Palavras-chave: Fonoaudiologia; deglutição; transtornos da deglutição; acidente vascular cerebral; indicadores de serviços.

\footnotetext{
${ }^{1}$ Universidade de São Paulo, Faculdade de Medicina, Hospital das Clínicas, Divisão de Fonoaudiologia do Instituto Central, São Paulo SP, Brasil; ${ }^{2}$ Universidade de São Paulo, Faculdade de Medicina, Departamento de Fisioterapia, Fonoaudiologia e Terapia Ocupacional, São Paulo SP, Brasil; ${ }^{3}$ Universidade de São Paulo, Faculdade de Medicina, Hospital das Clínicas, Divisão de Clínica Neurológica, Serviço de Neurologia de Emergência, São Paulo SP, Brasil.
}

Karoline Kussik de Almeida Leite (iD) https://orcid.org/0000-0002-7968-6249; Fernanda Chiarion Sassi (iD) https://orcid.org/0000-0002-7958-6280; Gisele Chagas de Medeiros (iD) https://orcid.org/0000-0001-7083-106X; Luiz Roberto Comerlatti iD https://orcid.org/0000-0002-0416-5190; Claudia Regina Furquim de Andrade (iD) http://orcid.org/0000-0001-9639-6377

Correspondence: Claudia Regina Furquim de Andrade; Rua Cipotânea, 51 - Cidade Universitária; 05360-160 São Paulo SP, Brasil; E-mail: clauan@usp.br Conflict of interest: The authors declare no conflicts of interest.

Received 26 November 2018; Received in final form 08 February 2019; Accepted 16 April 2019. 
Until the early 2000s, stroke was considered an inherent risk of aging and was rarely prioritized in health systems ${ }^{1}$. However, in 2007, a change occurred that led to the development of processes aimed at improving the effectiveness and efficiency of procedures adopted for post-stroke patients ${ }^{2}$.

Swallowing disorder, known as dysphagia, is present in more than $50 \%$ of patients with acute stroke, and this condition extends from stroke onset to the subsequent seven days $^{3}$. According to the literature, approximately $21 \%$ of stroke patients admitted to intensive care units develop aspiration pneumonia during hospitalization ${ }^{4}$, and the risk of death may increase by up to three times for these patients ${ }^{5}$. Thus, early assessment of dysphagia in post-stroke patients may minimize the risk of clinical complications ${ }^{6}$.

The high hospital cost associated with the care of patients with stroke is well documented in the literature, and dysphagia may increase these costs even more ${ }^{5}$. Patients with dysphagia due to stroke usually require a greater number of procedures (e.g., radiographic examinations) and more antibiotics, stay in the hospital longer, and frequently need to be transferred to backup hospitals ${ }^{6}$. The risk of pulmonary bronchoaspiration in patients with more severe dysphagia should also be considered a factor that contributes even further to increased costs?

In Brazil, the Manual of Strokes Care Routine, published by the Ministry of Health in $2013^{8}$, recommends that all patients who can maintain postural control and alertness for 15 minutes should be screened for dysphagia and, only after this evaluation, may oral feeding be permitted. However, this does not occur in many hospitals, as there is a lack of professionals specialized in the field. Therefore, the specific literature on dysphagia has advocated the establishment of specific indicators for the prioritization of speech therapy for patients $^{9}$. The establishment of these indicators will not only optimize bedside swallowing assessments but will also help reduce hospital costs, as early and safe return to oral feeding is essential for recovery of the patient's overall condition and to reduce the risk of exacerbation or readmission due to aspiration pneumonia? .

The aim of the present study was to identify indicators of the clinical prognosis of swallowing functionality in patients in the acute phase of stroke to establish indicators for prioritizing speech therapy care in these patients.

\section{METHODS}

We carried out a cross-sectional observational study. The project was approved by the Ethics Committee for Analysis of Research Projects of Hospital das Clínicas of the School of Medicine, University of São Paulo, Brazil (CAPPesq HCFMUSP no. 1.735.316). The procedures for data collection began after the informed consent form was signed by each patient or his/her legal guardian.

\section{Participants}

Adult patients admitted to the emergency room (ER) of Hospital das Clínicas who were diagnosed with ischemic stroke and, by medical request, were evaluated for swallowing at the bedside by the Speech and Language Pathology therapist from the same hospital between September 2016 and February 2017, were enrolled in this study.

The inclusion criteria adopted in this study were patients who: were aged $\geq 18$ years; had clinical stability according to medical records; had a confirmed diagnosis of acute stroke according to neurological medical evaluation and CT scan; in the acute phase of the disease (2-7 days after stroke); had no respiratory involvement; Glasgow Coma Scale (GCS) score $\geq 12$ (i.e. only patients with mild brain injury or normal neurologic conditions were included in order to guarantee that they were able to follow simple commands); absence of previous feeding complaints or changes in diet (food consistency); no previous use of an alternative feeding method; no tracheostomy; and no history of surgical procedures involving the head and neck region.

The steps for data collection are described below.

\section{Functional level of swallowing}

To determine the functional level of swallowing, the American Speech-Language-Hearing Association National Outcomes Measurement System(ASHA NOMS) was used ${ }^{10}$. This scale is a multidimensional instrument for assessing the supervision required for feeding and the type of diet, with scores ranging from 1-7. For the present study, the level of swallowing functionality was determined after completion of the Speech-Language Pathology Protocol for Dysphagia Risk Evaluation', which is routinely used by the Speech-Language Pathology Division at the hospital for swallowing assessment. The Dysphagia Risk Evaluation is indicated for early assessment of the dysphagia risk at the bedside, and its application includes administration of controlled volumes of water and mashed potatoes. The outcome indicates whether the patient can receive larger volumes of liquids/food and different food consistencies, as well as whether monitoring is required for safe feeding.

The functional level of deglutition of each patient was classified as follows: level 1) the individual cannot swallow anything safely through the mouth, and all nutrition and hydration are received through non-oral routes; level 2) the individual cannot swallow safely through the mouth but can ingest some items of various consistencies only during therapy sessions according to maximum and consistent use of clues, and an alternative route of feeding is necessary; level 3) an alternative feeding route is required, as the individual ingests less than $50 \%$ of his or her nutrition and hydration through the mouth, and/or swallowing is safe with moderate use of clues for the use of compensatory strategies, and/or the individual requires maximum diet restriction; level 4) swallowing is safe but often requires moderate use of clues for the use of compensatory strategies, and/or the individual has moderate dietary restrictions and/or still needs feeding by an alternative route 
or oral supplementation; level 5) swallowing is safe with minimal dietary restrictions and/or occasionally requires minimal clues for the use of compensatory strategies, and occasionally the individual can self-monitor, and all nutrition and hydration are received orally during meals; level 6) swallowing is safe and the individual eats and drinks independently, rarely requiring minimal clues for the use of compensatory strategies and often self-monitoring when difficulties occur, but avoiding some specific food items (e.g., popcorn and peanuts) and/ or additional feeding time (due to dysphagia) may be necessary; and level 7) the individual's ability to feed independently is not limited by swallowing function, and feeding is safe and efficient for all consistencies and compensatory strategies are effectively used when necessary.

To guarantee the reliability of the data, all speech therapists responsible for evaluation of swallowing at the bedside received specific training to define the functional level of swallowing. The functional level of swallowing was determined in the first clinical evaluation and following the resolution of dysphagia or at the time of hospital discharge. The patients were assessed by speech therapists with experience in evaluating and treating dysphagia, who were trained to apply the same treatment program.

All patients included in the study received individual treatment for swallowing rehabilitation until they were able to return to oral feeding or until they were discharged from hospital or moved to an intensive care treatment unit. Experienced speech-language pathologists, who were trained to deliver the same treatment program, saw all of the patients included in the study once a day for half an hour. Overall, treatment involved the use of direct and indirect therapy techniques to rehabilitate swallowing. Direct therapy involved controlled food offerings, even if in small volumes, for swallow training. Indirect therapy involved the use of exercises for oral motor training. It is important to highlight that swallowing and airway protection maneuvers were also used when necessary, in order to guarantee safe oral feeding and, consequently, the removal of the alternative feeding method.

\section{Indicators of clinical prognosis of swallowing functionality}

To determine the clinical prognostic factors associated with changes in swallowing functionality, the following demographic and clinical variables were included: age; sex; comorbidities; laterality of the ischemic stroke (right hemisphere, left hemisphere or bilateral hemispheres); impaired cerebral circulation (anterior or carotid region - involvement of the middle and anterior cerebral arteries, posterior or vertebral basilar region - involvement of the posterior cerebral artery ${ }^{11}$; time between evaluation of swallowing and speech therapy discharge (in days); time between speech-language assessment and hospital discharge (in days); number of speech therapy sessions until return to oral feeding; indications of requiring an alternative feeding method after swallowing assessment; indications for withdrawal of the alternative feeding method during speech therapy; number of speech therapy sessions before withdrawal of the alternative feeding method; and patient outcome (speech therapy discharge, hospital discharge, discontinuation of care due to worsening of the clinical condition, hospital transfer or death).

\section{Data analysis}

The data collected were statistically analyzed using SPSS version 25 software. Quantitative data were subjected to descriptive analysis (the mean and standard deviation) and inferential analysis to compare the groups (the Kruskal-Wallis test for multiple comparisons with post hoc analysis of pairs by Dunn's test with Bonferroni correction, if significant). Qualitative data were subjected to descriptive analysis (the total count and percentage) and inferential analysis to compare the groups (Pearson's chi-square test with post hoc peer analysis by Dunn's test with Bonferroni correction, if significant). For the present study, patients who presented with a functional swallowing level on the ASHA NOMS scale of 6 or 7 at the time of resolution of dysphagia or at hospital discharge were considered to have a positive result. The level of significance adopted in all analyses was $5 \%$.

\section{RESULTS}

The study sample consisted of 295 participants. For the purposes of statistical analysis, the patients were grouped according to the ASHA NOMS score obtained in the initial speech-language evaluation as follows: levels 1 and $2-$ ASHA1 (51 participants); levels 3, 4 and 5 - ASHA2 (96 participants); and levels 6 and 7 - ASHA3 (148 participants) ${ }^{12,13}$.

Table 1 shows the comparison of demographic variables and GCS scores between the groups.

The analyses indicated significant differences between groups for age and GCS score. The ASHA3 group were significantly younger compared with the other groups. The ASHA3 group had a significantly higher GCS score compared with the other groups. The ASHA2 group also scored significantly higher than the ASHA1 group.

Table 2 shows the comparisons of stroke laterality and the form of impairment of the cerebral circulation (anterior or carotid region, posterior or vertebrobasilar region).

No significant difference was found between the groups for ischemic stroke laterality. Concerning the cerebral circulation impairment, a significant difference was found between the ASHA1 and ASHA3 groups, and the ASHAl group had a greater number of patients with involvement of the cerebral circulatory system. No significant differences were observed in the other comparisons.

Table 3 shows the comparison of comorbidities. The total number of comorbidities was found to be higher than the number of participants in the sample since overlapping pathologies were observed (the same participant may present with more than one disease associated with stroke). 
Table 1. Between-group comparisons for age, sex and score on the Glasgow Coma Scale.

\begin{tabular}{|c|c|c|c|c|c|}
\hline Variable & ASHA1 & ASHA2 & ASHA3 & Multiple comparisons & Pairwise comparisons \\
\hline \multirow{3}{*}{ Age in years (mean $\pm S D$ ) } & \multirow{3}{*}{$73.1( \pm 13.8)$} & \multirow{3}{*}{$70.7( \pm 13.3)$} & \multirow{3}{*}{$62.4( \pm 14.0)$} & \multirow{3}{*}{$<0.001 *$} & ASHA1 = ASHA2; $p>0.999$ \\
\hline & & & & & ASHA $1 \neq$ ASHA3; $p<0.001 *$ \\
\hline & & & & & ASHA2 $\neq$ ASHA3; $p<0.001 *$ \\
\hline \multirow{2}{*}{ Sex } & $M=31$ & $M=50$ & $M=88$ & \multirow{2}{*}{0.450} & \multirow{2}{*}{-} \\
\hline & $F=20$ & $F=46$ & $F=60$ & & \\
\hline \multirow{3}{*}{ GCS (mean \pm SD) } & \multirow{3}{*}{$13.5( \pm 1.1)$} & \multirow{3}{*}{$14.4( \pm 0.7)$} & \multirow{3}{*}{$14.9( \pm 0.4)$} & \multirow{3}{*}{$<0.001 \star$} & $\mathrm{ASHA} 1 \neq \mathrm{ASHA} 2 ; \mathrm{p}>0.001 *$ \\
\hline & & & & & ASHA $1 \neq$ ASHA3; $p<0.001 *$ \\
\hline & & & & & $\mathrm{ASHA} 2 \neq \mathrm{ASHA} 3 ; \mathrm{p}<0.001 *$ \\
\hline
\end{tabular}

SD: standard deviation; M: male; F: female; GCS: Glasgow Coma Scale; ASHA1: levels 1 and 2 on the American Speech-Language-Hearing Association National Outcome Measurement System; ASHA2: levels 3, 4 and 5 on the American Speech-Language-Hearing Association National Outcome Measurement System; ASHA3: levels 6 and 7 on the American Speech-Language-Hearing Association National Outcome Measurement System; *: significant difference ( $<<0.05)$; Kruskal-Wallis test; Dunn's test with Bonferroni correction.

Table 2. Between-group comparisons for the laterality of the ischemic stroke and impaired cerebral circulation system.

\begin{tabular}{|c|c|c|c|c|c|}
\hline $\begin{array}{l}\text { Impaired cerebral circulation } \\
\text { system }\end{array}$ & ASHA1 & ASHA2 & ASHA3 & Multiple comparisons & Pairwise comparisons \\
\hline Left & $28(24.9 \%)$ & $55(57.3 \%)$ & $83(56.1)$ & & \\
\hline Right. & $21(41.2 \%)$ & $39(40.6 \%)$ & $60(40.5 \%)$ & 0.960 & - \\
\hline Bilateral & $2(3.9 \%)$ & $2(2.1 \%)$ & $5(3.4 \%)$ & & \\
\hline Posterior & $49(96.1 \%)$ & $87(90.6 \%)$ & $121(81.8 \%)$ & $0.014^{\star}$ & $\begin{array}{c}\text { ASHA1 }=\text { ASHA2 } \\
p>0.999 \\
\text { ASHA1 } \neq \text { ASHA3 } \\
p=0.026^{*} \\
\text { ASHA2 }=A S H A 3 \\
p=0.131\end{array}$ \\
\hline
\end{tabular}

\%: percentage of participants; ASHA1: levels 1 and 2 on the American Speech-Language-Hearing Association National Outcome Measurement System; ASHA2: levels 3, 4 and 5 on the American Speech-Language-Hearing Association National Outcome Measurement System; ASHA3: levels 6 and 7 on the American Speech-Language-Hearing Association National Outcome Measurement System; *: significant difference $(p<0.05)$ Pearson's Chi-Square test, Dunn's test with Bonferroni correction.

Table 3. Between-group comparisons for the presence of comorbidities.

\begin{tabular}{|c|c|c|c|c|c|}
\hline Comorbidity & ASHA1 & ASHA2 & ASHA3 & Multiple comparisons & Pairwise comparisons \\
\hline Systemic arterial hypertension & $33(64.7 \%)$ & $64(67.4 \%)$ & $87(58.4 \%)$ & 0.345 & - \\
\hline Diabetes mellitus & $18(35.3 \%)$ & $25(26.3 \%)$ & $43(28.9 \%)$ & 0.521 & - \\
\hline Cardiopathy & $11(21.6 \%)$ & $20(21.1 \%)$ & $23(15.4 \%)$ & 0.437 & - \\
\hline Dyslipidemia & $3(5.9 \%)$ & $12(12.6 \%)$ & $23(15.4 \%)$ & 0.214 & - \\
\hline Dementia & $8(15.7 \%)$ & $8(8.4 \%)$ & $0(0 \%)$ & $<0.001 *$ & $\begin{array}{c}\text { ASHA1 }=\text { ASHA2 } \\
p>0.195 \\
\text { ASHA1 } \neq \text { ASHA3 } \\
p<0.001^{*} \\
\text { ASHA2 } \neq \text { ASHA3 } \\
p=0.014^{*}\end{array}$ \\
\hline Previous ischemic stroke & $10(19.6 \%)$ & $17(17.9 \%)$ & $22(14.8 \%)$ & 0.668 & - \\
\hline Smoking & $3(5.9 \%)$ & $12(12.6 \%)$ & $15(10.1 \%)$ & 0.438 & - \\
\hline Alcoholism & $0(0 \%)$ & $4(4,2 \%)$ & $8(5.4 \%)$ & 0.246 & - \\
\hline Total comorb/pat (mean \pm SD) & $1.7( \pm 0.9)$ & $1.7( \pm 1.1)$ & $1.5( \pm 1.2)$ & 0.237 & - \\
\hline
\end{tabular}

comorb/pat: comorbidities per patient; \%: percentage of patients; ASHA1: levels 1 and 2 on the American Speech-Language-Hearing Association National Outcome Measurement System; ASHA2: levels 3, 4 and 5 on the American Speech-Language-Hearing Association National Outcome Measurement System: ASHA3: levels 6 and 7 on the American Speech-Language-Hearing Association National Outcome Measurement System; *: significant difference ( $p<0.05)$ Pearson's Chi-Square test, Dunn's test with Bonferroni correction.

A significant difference was observed between the groups for the presence of comorbid dementia. The ASHA3 group had a significantly lower number of participants with dementia compared with the other groups. No significant differences were found in the other comparisons.

Table 4 shows the comparisons between the groups for clinical variables and the outcomes of the patients. 
Table 4. Between-group comparisons for the clinical variables and patient outcome.

\begin{tabular}{|c|c|c|c|c|c|}
\hline $\begin{array}{l}\text { Clinical variables and } \\
\text { patient outcome }\end{array}$ & ASHA1 & ASHA2 & ASHA3 & Multiple comparisons & Pairwise comparisons \\
\hline $\begin{array}{l}\text { Time between assessment } \\
\text { and speech therapy, in days } \\
\text { (mean } \pm \text { SD) }\end{array}$ & $14.4( \pm 7.1)$ & $6.7( \pm 3.9)$ & $1.5( \pm 2.0)$ & $<0.001 *$ & $\begin{array}{c}\text { ASHA1 }=\text { ASHA2 } \\
p=0.999 \\
\text { ASHA1 } \neq \text { ASHA3 } \\
p<0.001 * \\
\text { ASHA2 } \neq \text { ASHA3 } \\
p<0.001 *\end{array}$ \\
\hline $\begin{array}{l}\text { Time between swallowing } \\
\text { assessment and hospital } \\
\text { discharge, in days (mean } \pm \\
\text { SD) }\end{array}$ & $12.9( \pm 8.6)$ & $7.9( \pm 9.7)$ & $2.8( \pm 3.7)$ & $<0.001 *$ & $\begin{array}{c}\text { ASHA1 } \neq \text { ASHA2 } \\
p<0.049 * \\
\text { ASHA1 } \neq \text { ASHA3 } \\
p<0.001 * \\
\text { ASHA2 } \neq \text { ASHA3 } \\
p<0.001 *\end{array}$ \\
\hline $\begin{array}{l}\text { Number of speech therapy } \\
\text { sessions until safe oral } \\
\text { feeding (mean } \pm S D \text { ) }\end{array}$ & $2.9( \pm 2.5)$ & $1.1( \pm 0.2)$ & $0.0( \pm 0.0)$ & $<0.001^{\star}$ & $\begin{array}{c}\text { ASHA1 } \neq \text { ASHA2 } \\
p<0.001 * \\
\text { ASHA1 } \neq \text { ASHA3 } \\
p<0.001 * \\
\text { ASHA2 }=\text { ASHA3 } \\
p=0.431\end{array}$ \\
\hline $\begin{array}{l}\text { Number of participants with } \\
\text { alternative feeding method } \\
\text { after swallowing assessment } \\
\text { (total number/\%) }\end{array}$ & $48(94.1 \%)$ & $13(13.5 \%)$ & $0(0 \%)$ & $<0.001 * \star$ & $\begin{array}{c}\text { ASHA } 1 \neq \text { ASHA2 } \\
p<0.001 * \\
\text { ASHA } 1 \neq \text { ASHA3 } \\
p<0.001^{*} \\
\text { ASHA } 2 \neq \text { ASHA3 } \\
p=0.030^{*}\end{array}$ \\
\hline $\begin{array}{l}\text { Number of participants } \\
\text { who had alternative } \\
\text { feeding method removed } \\
\text { after speech therapy (total } \\
\text { number/\%) }\end{array}$ & $13(25.5 \%)$ & $16(16.7 \%)$ & $6(4.1 \%)$ & $0.001 * \star$ & $\begin{array}{c}\text { ASHA } 1 \neq \text { ASHA2 } \\
p=0.016 * \\
\text { ASHA1 } \neq \text { ASHA3 } \\
p=0.001 * \\
\text { ASHA2 }=\text { ASHA3 } \\
p>0.999\end{array}$ \\
\hline $\begin{array}{l}\text { Number of speech therapy } \\
\text { sessions until alternative } \\
\text { feeding method removal } \\
\text { (mean } \pm \text { SD) }\end{array}$ & $6.8( \pm 3.2)$ & $3.7( \pm 4.0)$ & $1.5( \pm 0.5)$ & $0.001 *$ & $\begin{array}{c}\text { ASHA } 1 \neq \text { ASHA2 } \\
p>0.195 \\
\text { ASHA1 } \neq \text { ASHA3 } \\
p<0.001^{*} \\
\text { ASHA2 }=\text { ASHA3 } \\
p=0.406\end{array}$ \\
\hline Speech therapy discharge & $5(9.8 \%)$ & $20(20.8 \%)$ & $113(76.4 \%)$ & $<0.001 *$ & $\begin{array}{c}\text { ASHA1 } \neq \text { ASHA2 } \\
p<0.001 * \\
\text { ASHA1 = ASHA3 } \\
p=0.608 \\
\text { ASHA2 } \neq \text { ASHA3 } \\
p<0.001 *\end{array}$ \\
\hline Hospital discharge & $14(27.5 \%)$ & $68(70.8 \%)$ & $35(23.6 \%)$ & $<0.001 *$ & $\begin{array}{c}\text { ASHA1 } \neq \text { ASHA2 } \\
p<0.001 * \\
\text { ASHA1 }=\text { ASHA3 } \\
p>0.999 \\
\text { ASHA2 } \neq \text { ASHA3 } \\
p<0.001 *\end{array}$ \\
\hline
\end{tabular}

Continue 


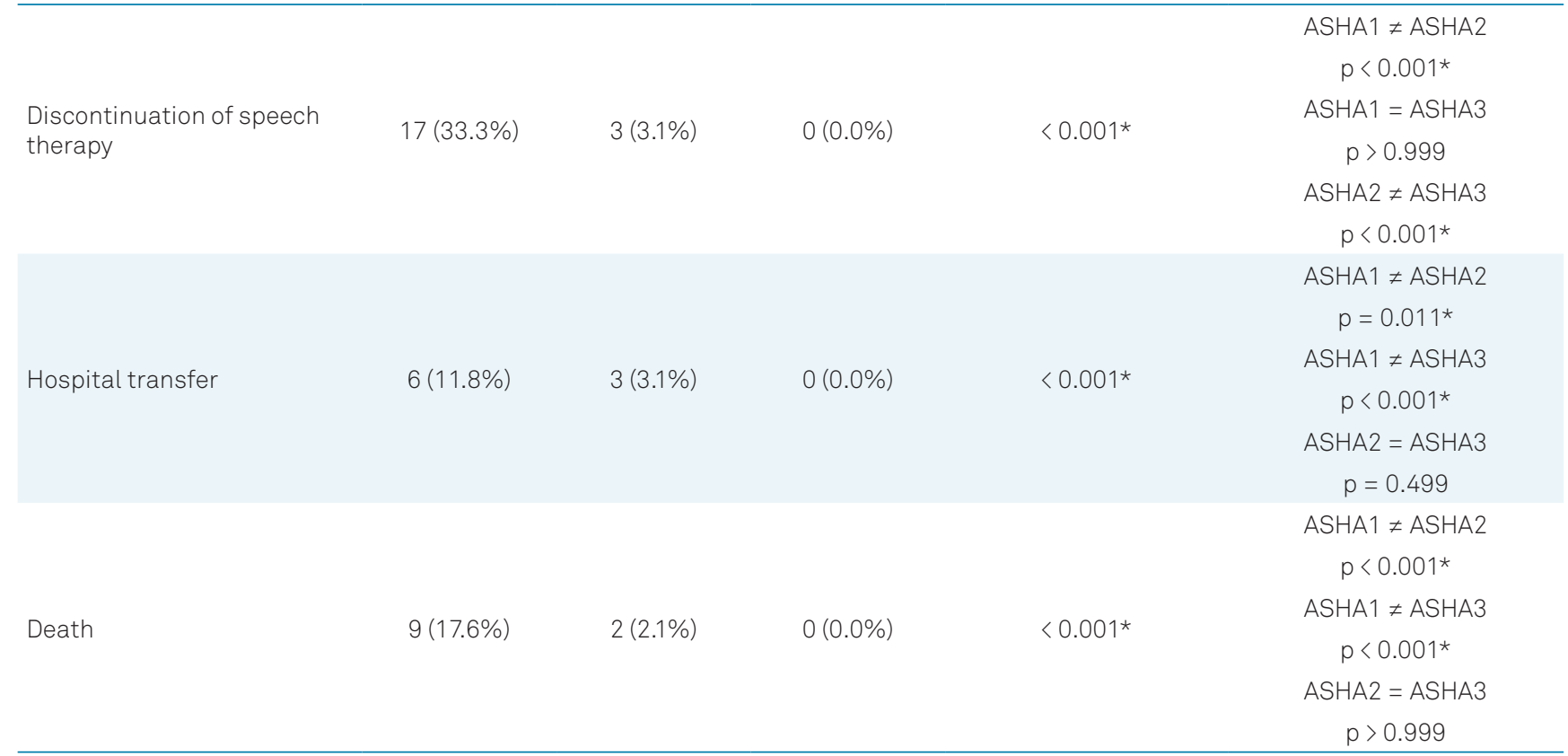

\%: percentage of participants; SD: standard deviation; ASHA1: levels 1 and 2 on the American Speech-Language-Hearing Association National Outcome Measurement System; ASHA2: levels 3, 4 and 5 on the American Speech-Language-Hearing Association National Outcome Measurement System; ASHA3: levels 6 and 7 on the American Speech-Language-Hearing Association National Outcome Measurement System; *: significant difference ( $p<0.05)$, Pearson's Chi-Square test, Dunn's test with Bonferroni correction.

Significant differences were observed in all variables tested. In general, the ASHA1 and ASHA2 groups presented with worse results compared with the ASHA3 group.

\section{DISCUSSION}

In the present study, patients with poor swallowing functionality had a mean age older than 70 years, greater impairment of the anterior cerebral circulation after stroke and a worse GCS score ( $\leq 14$ points), required more time to start speech therapy for swallowing rehabilitation, were hospitalized longer, used an alternative feeding route, required more speech therapy sessions to withdraw the alternative feeding route, required more time to return to oral feeding, had a worse outcome (they were discharged from speech therapy less often and were more likely to die) and presented with a higher frequency of dementia.

The impact of age on the increase in the incidence of dysphagia has been extensively documented in the literature, corroborating the results of the present study. The prevalence of dysphagia in the elderly population (between $20 \%$ and $40 \%$ for individuals over 55 years) is higher than that in the general population (between $6 \%$ and $9 \%)^{14,15}$. The aging process is usually associated with brain atrophy, deterioration of neural function and reduced muscle mass ${ }^{16}$, and these changes may have an impact on the swallowing process. Studies have documented reduced pharyngeal contraction amplitude, pharyngeal shortening, decreased propulsion/tongue strength and decreased palatine velum strength to assist displacement of a bolus in healthy elderly individuals ${ }^{17}$. The effects of age on reducing isometric forces and the pressure required for swallowing seem to progress with age ${ }^{18}$. The literature also points to the association between age and the decrease in activation of airway protection mechanisms during swallowing, favoring bronchopulmonary penetration/aspiration ${ }^{19}$.

In our study sample, patients with worse swallowing functionality (ASHA1), in addition to being older, also showed a lower level of consciousness and a higher frequency of dementia as a comorbidity. According to the literature, the prevalence of dysphagia in the elderly population increases substantially, reaching $80 \%$ in the presence of age-related diseases such as stroke and dementia ${ }^{7}$. Delayed triggering of the swallowing reflex and reduction of laryngeal elevation have been associated with bronchopulmonary aspiration in post-stroke patients ${ }^{20}$. In patients with dementia, the literature points out that the prevalence of dysphagia varies between $13 \%$ and $57 \%^{21}$. According to the literature, aspiration of liquids is the main characteristic observed in this population ${ }^{22}$. In addition, the literature also describes that patients with dementia usually present with the interruption of actions involving the preparatory phase of swallowing as a consequence of the related cognitive deficits, as well as inadequate oral motor control of the bolus, delayed swallowing reflex, reduction in laryngeal elevation and valleculae residue, all of which contribute to the increased morbidity and premature death ${ }^{23}$. Although the patients included in this study did not report previous swallowing difficulties and changes in diet consistency 
(i.e. inclusion criteria), we cannot prove that these patients did not have previous dysphagia.

The present study did not find differences between the groups for the laterality of brain injury. Although the laterality of swallowing has already been investigated, the exact mechanism involved in this process remains unknown ${ }^{3}$. One study investigated this swallowing laterality in healthy participants and found left hemisphere dominance in $35 \%$ of them, right hemisphere dominance in $7 \%$, and non-laterality of swallowing in the other participants ${ }^{24}$. In another study using magnetic resonance imaging, the researchers identified activation of the following brain areas during swallowing: the primary motor cortex, primary somatosensory cortex, cortical supplementary motor area, prefrontal cortex, transverse temporal gyrus, insular cortex, internal capsule, cingulate gyrus, speech areas, auditory association area and sensory-motor association areas ${ }^{25}$. In this study, lateralization toward the right hemisphere was greater than that toward the left hemisphere during swallowing tasks. Thus, the lateralization of brain activity in swallowing, both in normal individuals and in individuals after stroke, remains controversial.

Studies that classify dysphagia based on vascular territory are rare and also present divergent results. A previous study indicated that dysphagia is more frequently observed in patients with middle cerebral artery infarction and is significantly more associated with the size of the lesion than the site of the lesion ${ }^{26}$. Other studies have found that signs of bronchopulmonary aspiration and pharyngeal dysfunction are frequently observed in patients with involvement of the posterior vascular territory $y^{26,27}$. The present study was performed in an ER unit that does not keep severely ill patients; these patients are referred to intensive care units. Therefore, patients with posterior cerebral artery infarction with brainstem involvement, who usually exhibit more severe clinical features and greater swallowing impairment ${ }^{28,29}$, do not remain in the ER. This fact may explain why, in the present study, the group with the worst swallowing function (ASHA1) had greater impairment of the anterior cerebral circulatory system.

Regarding outcomes, our results indicated that patients with poor swallowing functionality at the initial evaluation were less often discharged from speech therapy and were more likely to die compared with those in the other groups. In the hospital where the data collection in this work was performed, because it is a tertiary service, clinical stability is not always related to complete swallowing rehabilitation. Therefore, an individual may be discharged with resolution of the clinical condition but may still require speech therapy intervention. In this study, only $47 \%$ of the individuals were discharged from speech therapy, while the others were referred to rehabilitation centers for speech therapy followups. This result corroborates the data in the literature indicating that $50 \%$ of post-stroke patients remain with dysphagia after hospital discharge and that more severe dysphagia is a predictor of a unfavorable outcome and a higher mortality rate ${ }^{30}$. Furthermore, according to the literature, the need for an alternative feeding pathway in post-stroke patients also showed a correlation with a higher mortality rate and a worse outcome ${ }^{26,30}$, despite the placement of a feeding tube to reduce the risk of bronchopulmonary aspiration ${ }^{31}$. In the present study, $94 \%$ of the ASHA1 patients had an indication for an alternative feeding route after the speech-language evaluation. Use of a feeding tube may promote colonization of the oropharynx with harmful bacteria ${ }^{32,33}$, and most cases of aspiration pneumonia are of bacterial origin ${ }^{33}$.

The present study has some limitations. Stroke extension was not included as an analysis variable. The comparison of the outcomes of patients with different stroke severities in future studies may help better define speech-language pathology rehabilitation in this population, as the severity of stroke is described as being a risk factor for dysphagia ${ }^{26,34}$. Regarding the presence of dysphagia prior to the stroke, patients did not have a formal swallowing assessment on file to exclude this condition. Although patients did not report previous swallowing difficulties, this possibility must not be discarded and may have influenced our results. Moreover, the identification of dysphagia in this study was clinical, and confirming the diagnosis by objective evaluation of swallowing is important. Videofluoroscopy of swallowing is considered the "gold standard" for evaluating bronchopulmonary penetration/aspiration. In the present study, performing videofluoroscopy in the individuals was not possible due to limitations of the clinical condition, displacement, positioning, and high cost, among others. Finally, the results presented cannot be generalized, as this is a study of a single care center for patients with acute stroke.

In conclusion, the results suggest that patients with acute stroke admitted to ERs with an age $\geq 70$ years, a GCS score $\leq 14$, involvement of the anterior cerebral circulatory system and dementia should be prioritized by a speech and language therapist for swallowing evaluation and rehabilitation.

\section{References}

1. McHugh G, Swain ID. A comparison between reported therapy staffing levels and the department of health therapy staffing guidelines for stroke rehabilitation: a national survey. BMC Health Serv Res. 2014 May;14(1):216. https://doi.org/10.1186/1472-6963-14-216
2. World Health Organization - WHO. Stroke, cerebrovascular accident. 2017 [cited 2017 Sep 23]. Available from: https://www.who.int/topics/cerebrovascular_ accident/en/ 
3. Yang S, Choi KH, Son YR. The effect of stroke on pharyngeal laterality during swallowing. Ann Rehabil Med. 2015 Aug;39(4):509-16. https://doi.org/10.5535/arm.2015.39.4.509

4. Titsworth WL, Abram J, Fullerton A, Hester J, Guin P, Waters MF, et al. Prospective quality initiative to maximize dysphagia screening reduces hospital-acquired pneumonia prevalence in patients with stroke. Stroke. 2013 Nov;44(11):3154-60. https://doi.org/10.1161/STROKEAHA.111.000204

5. Bonilha HS, Simpson AN, Ellis C, Mauldin P, Martin-Harris $\mathrm{B}$, Simpson K. The one-year attributable cost of poststroke dysphagia. Dysphagia. 2014 Oct;29(5):545-52. https://doi.org/10.1007/s00455-014-9543-8

6. Martino R, Silver F, Teasell R, Bayley M, Nicholson G, Streiner DL, et al. The Toronto Bedside Swallowing Screening Test (TOR-BSST): development and validation of a dysphagia screening tool for patients with stroke. Stroke. 2009 Feb;40(2):555-61. https://doi.org/10.1161/STROKEAHA.107.510370

7. Martino R, Foley N, Bhogal S, Diamant N, Speechley M, Teasell R. Dysphagia after stroke: incidence, diagnosis, and pulmonary complications. Stroke. 2005 Dec;36(12):2756-63. https://doi.org/10.1161/01.STR.0000190056.76543.eb

8. Ministério da Saúde (BR). Manual de rotinas para atenção ao AVC. Brasília, DF: Minsitério da Saúde; 2013.

9. Moraes DP, Sassi FC, Mangilli LD, Zilberstein B, de Andrade CR. Clinical prognostic indicators of dysphagia following prolonged orotracheal intubation in ICU patients. Crit Care. 2013 Oct;17(5):R243. https://doi.org/10.1186/cc13069

10. American Speech-Language Hearing Association National Outcome Measurement System (NOMS). Adult speech-language pathology training manual. Rockville, MD: American Speech-Language Hearing Association; 1998.

11. Tatu L, Moulin T, Bogousslavsky J, Duvernoy H. Arterial territories of the human brain: cerebral hemispheres. Neurology. 1998 Jun;50(6):1699-708. https://doi.org/10.1212/WNL.50.6.1699

12. Medeiros GC, Sassi FC, Mangilli LD, Zilberstein B, Andrade CR. Clinical dysphagia risk predictors after prolonged orotracheal intubation. Clinics (Sao Paulo). 2014 Jan;69(1):8-14. https://doi.org/10.6061/clinics/2014(01)02

13. Medeiros GC, Sassi FC, Zambom LS, Andrade CR. Correlation between the severity of critically ill patients and clinical predictors of bronchial aspiration.J Bras Pneumol. 2016;42:114-20. https://doi.org/10.1590/S1806-37562015000000192

14. Shune SE, Moon JB, Goodman SS. The effects of age and preoral sensorimotor cues on anticipatory mouth movement during swallowing. J Speech Lang Hear Res. 2016 Apr;59(2):195-205. https://doi.org/10.1044/2015_JSLHR-S-15-0138

15. Aslam M, Vaezi MF. Dysphagia in the elderly. Gastroenterol Hepatol (NY). 2013 Dec;9(12):784-95.

16. Masoro EJ. Biology of aging. Current state of knowledge. Arch Intern Med. 1987 Jan;147(1):166-9. https://doi.org/10.1001/archinte.1987.00370010164033

17. Dejaeger E, Pelemans W, Ponette E, Joosten E. Mechanisms involved in postdeglutition retention in the elderly. Dysphagia. 1997;12(2):63-7. https://doi.org/10.1007/PL00009520

18. Nicosia MA, Hind JA, Roecker EB, Carnes M, Doyle J, Dengel GA, et al. Age effects on the temporal evolution of isometric and swallowing pressure.J Gerontol A Biol Sci Med Sci. 2000 Nov;55(11):M634-40. https://doi.org/10.1093/gerona/55.11.M634
19. Wang CM, Chen JY, Chuang CC, Tseng WC, Wong AM, Pei YC. Aging-related changes in swallowing, and in the coordination of swallowing and respiration determined by novel non-invasive measurement techniques. Geriatr Gerontol Int. 2015 Jun;15(6):73644. https://doi.org/10.1111/ggi.12343

20. Logemann JA, Pauloski BR, Rademaker AW, Colangelo LA, Kahrilas PJ, Smith CH. Temporal and biomechanical characteristics of oropharyngeal swallow in younger and older men. J Speech Lang Hear Res. 2000 Oct;43(5):1264-74. https://doi.org/10.1044/jslhr.4305.1264

21. Alagiakrishnan K, Bhanji RA, Kurian M. Evaluation and management of oropharyngeal dysphagia in different types of dementia: a systematic review. Arch Gerontol Geriatr. 2013 Jan-Feb;56(1):1-9. https://doi.org/10.1016/j.archger.2012.04.011

22. Painter V, Le Couteur DG, Waite LM. Texture-modified food and fluids in dementia and residential aged care facilities. Clin Interv Aging. 2017 Aug;12:1193-203. https://doi.org/10.2147/CIA.S140581

23. Lin LC, Watson R, Wu SC. What is associated with low food intake in older people with dementia? J Clin Nurs. 2010 Jan;19(1-2):53-9. https://doi.org/10.1111/j.1365-2702.2009.02962.x

24. Seta H, Hashimoto K, Inada H, Sugimoto A, Abo M. Laterality of swallowing in healthy subjects by AP projection using videofluoroscopy. Dysphagia. $2006 \mathrm{Jul}$;21(3):191-7. https://doi.org/10.1007/s00455-006-9021-z

25. Mosier KM, Liu WC, Maldjian JA, Shah R, Modi B. Lateralization of cortical function in swallowing: a functional MR imaging study. AJNR Am J Neuroradiol. 1999 Sep;20(8):1520-6.

26. Paciaroni M, Mazzotta G, Corea F, Caso V, Venti M, Milia P, et al. Dysphagia following Stroke. Eur Neurol. 2004;51(3):162-7. https://doi.org/10.1159/000077663

27. Kim SY, Kim TU, Hyun JK, Lee SJ. Differences in videofluoroscopic swallowing study (VFSS) findings according to the vascular territory involved in stroke. Dysphagia. 2014 Aug;29(4):444-9. https://doi.org/10.1007/s00455-014-9525-x

28. Lang IM. Brain stem control of the phases of swallowing. Dysphagia. 2009 Sep;24(3):333-48. https://doi.org/10.1007/s00455-009-9211-6

29. Mihai PG, Otto M, Domin M, Platz T, Hamdy S, Lotze M. Brain imaging correlates of recovered swallowing after dysphagic stroke: A fMRI and DWI study. Neuroimage Clin. 2016 May;12:1013-21. https://doi.org/10.1016/j.nicl.2016.05.006

30. Arnold M, Liesirova K, Broeg-Morvay A, Meisterernst J, Schlager M, Mono ML, et al. Dysphagia in acute stroke: incidence, burden and impact on clinical outcome. PLoS One. 2016 Feb;11(2):e0148424. https://doi.org/10.1371/journal.pone.0148424

31. Langdon PC, Lee AH, Binns CW. High incidence of respiratory infections in 'nil by mouth' tube-fed acute ischemic stroke patients. Neuroepidemiology. 2009;32(2):107-13. https://doi.org/10.1159/000177036

32. Langmore SE, Skarupski KA, Park PS, Fries BE. Predictors of aspiration pneumonia in nursing home residents. Dysphagia. 2002;17(4):298-307. https://doi.org/10.1007/s00455-002-0072-5

33. Millns B, Gosney M, Jack Cl, Martin MV, Wright AE. Acute stroke predisposes to oral gram-negative bacilli- a cause of aspiration pneumonia? Gerontology. 2003 May-Jun;49(3):173-6. https://doi.org/10.1159/000069171

34. Okubo PC, Fábio SR, Domenis DR, Takayanagui OM. Using the National Institute of Health Stroke Scale to predict dysphagia in acute ischemic stroke. Cerebrovasc Dis. 2012;33(6):501-7. https://doi.org/10.1159/000336240 